\title{
Enriching the Experience for Government Documents Student Workers
}

Josh Sopiarz

A cknowledging that student employees fill essential positions in academic libraries across the country is not a particularly radical act. Indeed, it would appear that things have always been this way. Still, something new is undeniably afoot and the idea that we can be doing more for our student employees is spreading. For years now we have asked students to work late into the night during the week or on weekends, often without direct supervision. More and more we have been asking them to shoulder significant responsibilities at public service desks when other library professionals are unavailable. Our students have responded heroically, and their presence, more than ever, allows academic librarians to pursue other professional activities-to teach, conduct research, perform service, and travel to conferences.

At the same time, we ask ourselves: what more can we be doing for our students? How can we be sure work in the library translates into real skills and experience that will benefit them personally and professionally after graduation? Are we growing the "whole student" or not? All this is to say that along with recent trends a significant body of work has evolved on the topic of student employees in the twenty-first century academic library. What is missing still, however, is any discussion on Government Documents student workers, specifically. In an attempt to address this omission, the following details some opportunities available to Documents supervisors looking to enhance the experience for their student workers.

\section{Documents vs. Traditional Student Employees}

In many instances the work Documents student employees does looks the same as the work of their peers in other departments. Bradley Tolppanen and Janice Derr mapped those tasks nicely in their 2009 "A Survey of the Duties and Job Performance of
Student Assistants in Access Services." Through their survey, Tolppanen and Derr demonstrated that of 85 regularly assigned academic library tasks 19 can be classified as "core" after determining that $60 \%$ of their survey respondents assigned those specific tasks on a daily or weekly basis. These core tasks run the gamut from "checkout/renew/discharge library materials" which $97.8 \%$ of respondents assigned daily or weekly to "oversee library detection gates and respond to alarms" assigned by $62.4 \%$ of respondents. ${ }^{1}$ The authors characterize the tasks on this list as "all basic" and "rather straightforward," but they also stress that they are "essential."

Without question, Documents student workers perform many of these core "basic" and "essential" tasks. They "shelve stacks and periodicals collections" and "search for books and other items (missing, lost, claimed returned)," etc. ${ }^{3}$ In addition, however, Documents students perform unique tasks their peers in more traditional library employment roles do not. We ask our students to immerse themselves in a separate Documents lexicon as they learn the SuDocs classification scheme; compile discard lists; deal in shipping manifests, irregular items, and seldom heard of government agencies; and we challenge them to familiarize themselves with alien systems and media like FDsys and microfiche. By virtue, the uniqueness of the work they do tends to have an isolating effect on our Documents student employees.

There are other differences worth noting, too. Chiefly, that Documents students very often belong to much smaller departments than their peers. Circulation, reference, and technical services departments are (typically) larger than Documents departments and they tend to employ the majority of an academic library's student workers. Students in those departments have more and better opportunities to make friends, study with peers during down times, and participate in peer-to-peer 
learning while on the job. Even so, there are great opportunities for Documents students. And these opportunities have the potential to benefit both students and supervisors in exciting and meaningful ways.

\section{Unique Circumstances}

Some of the same circumstances mentioned above-smaller departments, isolation-can also be a boon to Documents supervisors and their student workers. For one, supervisors can work more closely with students when there are fewer of them, thus Documents supervisors are often able to get to know their students better both personally and professionally. Similarly, students in these situations are afforded an inside look into the daily lives of a living, breathing, practicing library professional in ways their peers are not; understanding flows both ways in these situations. Also, fewer students means supervisors can pay better attention to the tasks at hand since managing fewer people translates to less time spent on clerical tasks like keeping track of timesheets, making schedules, tracking down substitutes if a student flakes on a shift or if something comes up, and other time-sucking minutiae. This also benefits students as they receive more direct attention from their supervisors.

One last, and probably, obvious thing worth mentioning is that the turnover rate amongst student employees in academic libraries is notoriously high. The rate is so high, in fact, one library administrator used it as an excuse to eliminate student worker positions in favor of another more predictable model. ${ }^{4}$ Still, (assuming they supervise fewer students than their circulation, reference, or technical services peers) the Documents supervisor has the advantage here. Supervisors with fewer students are better able to anticipate their students' plans and schedules term-to-term. In many instances, because they have fewer student employees to manage, Documents supervisors can work with their students and plan for the future with a kind of certainty a lot of other library supervisors cannot. It is not out of the question for a Documents supervisor to meet with his/ her student workers each semester to glean whether or not they intend to stay on doing Documents work in the library for the duration of the next term. This sort of foresight breeds consistency and allows the Documents supervisor to plan potentially significant projects with confidence.

In this clearer and more stable environment Documents supervisors are better able to hand select the best-qualified student employees, retain them, and assign them higher order tasks that will benefit both the supervisor and the student employee. Further, operating in this way Documents supervisors can institute a system whereby student workers cycling out of the library because they are graduating or taking a job or internship can train their replacements in the department. Training student employees takes up an unnecessarily large amount of a supervisor's time each term. Planning ahead and teaching students to train their peers is one way to both free up significant time each term and allow students to get the kind of experience potential employers will be looking for when they review candidate resumes.

Tolppanen and Derr discovered that fewer than $8 \%$ of supervisors assign their students higher order tasks such as peer training, processing materials, or data entry. ${ }^{5}$ And in a study of their own, Lori Mestre and Jessica LeCrone at the Undergraduate Library at the University of Illinois at Urbana-Champaign confirmed that completing higher order tasks enhances students' skills and potential for employment post-graduation. In addition, they assert, libraries "gain perspectives and contributions that can potentially help staff and librarians better relate to their public," and "help free up their time so they can focus on other areas." Documents supervisors have the opportunity and the motivation to assign these, and other even more exciting and ambitious, higher order tasks. In doing so, they help students immensely while also creating time for their own professional endeavors.

Research demonstrates that library student employees are eager for higher order work assignments and experiences. The benefits to both supervisors and students have been proven as well. But before assigning tasks, if they are to truly maximize the benefits for everyone involved, Documents supervisors must:

- Plan ahead and be deliberate when creating assignments;

- Make intentions and expectations clear;

- Set achievable goals and enact reasonable deadlines;

- Remain flexible;

- Conduct assessments and solicit feedback as necessary, and;

- Remember student employees are-above all elsestudents first, and that their own academic work has priority.

So, what might this look exactly?

\section{Example}

By summer 2015 I had been thinking a lot about how I could enhance the experience for my Documents student workers. Partly, I was unhappy having them sitting in a cubicle, isolated, sifting through superseded documents and compiling discard lists and the like while their peers in access services were loosed on the building, manning service desks, maintaining the "big" collections, and forming friendships. At the time my library 


\section{Enriching the Experience for Government Documents Student Workers}

employed 15 student workers. The 2 students in Documents never worked together (there is not room) and had few chances to socialize (commiserate?) with each other on the job. At the same time university administration was pushing for enhanced student experiences and more peer-to-peer participation. My university was eager to implement High Impact Practices (HIPs) across the board, and I began to plan appropriate activities for my student worker. By the time the term started I was down to just a single student working 37.5 hours a month. ${ }^{7}$

Earlier in his library career I was able to arrange for my student to be cross-trained to work the circulation desk. While not necessarily a "high impact" move, the cross-training diversified his skill set and afforded him the opportunity to work and form social bonds with the other students in the library. Also, he was earning a good reputation in the library as an eager and reliable team member. As library projects arose, I was often asked if my student would like to lend a hand. These requests led to a firstof-its-kind meeting with my Documents student to discuss truly diversifying his student employee experience. During that meeting I asked if he was comfortable working with other library supervisors and made clear that he was able to decline projects at any time. He seemed eager to contribute.

Keeping in mind that I wanted my students participating in as many HIP opportunities as possible moving forward, I was happy to see my Docs student agree to help the library's archivist and web manager with two projects digitizing syllabi and historical copies of the student newspaper early in the Fall 2015 term. To be sure, finding the time to work at the circulation desk or on these digitization projects required patience and inter-departmental planning (archives and web services had no students of their own). All this also involved a good deal of schedule shuffling to make sure service points were covered, deadlines were met, and that Documents work continued uninterrupted.

I believe it was all worth it as I found my student was glad for the experience and that the supervisors were generally thrilled to have the help he provided. More, I recognized the experiences seemed to positively embolden my student employee. In a short time, he met more students and library staff and faculty and he comported himself more confidently when in groups with these people. Soon he was speaking more confidently about the library and even started identifying projects he would like to tackle. It was not long after that that he graduated to proposing projects and timelines for completion to me.

For example, after just a couple months in this newly diversified role, my student worker approached me with ideas for processing a sizable collection of books a long-time faculty member had donated to the library. He was aware of an app we could use to keep track of the collection and later transfer the data to Microsoft Excel in case we wanted to add the data to our website or digital repository. He was happy to inform me of this app and demonstrate its usefulness for the kind of project we were facing. I learned a great deal from that proposal and I believe the student gained invaluable insight and practice, too. As I write, he is at work on the donation project.

As the Fall 2015 semester wound to its end, I conducted a first of its kind (for me) assessment to gauge how well (or not) the new more deliberate efforts to enhance the Documents experience were working. I decided to conduct a mid-year assessment so that there would be time to make adjustments during the spring semester while business as usual was the norm in the library rather than the summer when scheduling gets tricky and activity slows considerably. I was impressed to learn just how involved the projects my student had assisted on had been. I was similarly excited to see that the student found the experiences worthwhile. And, although he did lament that much of his work at the circulation desk was clearly lower order, he identified that the more-involved projects offset the malaise. Most promising was the student's indication that he would like to continue doing higher order work.

Interestingly, when asked about developing friendships with the other student workers my student seemed politely indifferent. I wonder if this aspect of student employment is as important as I initially thought. I realize that everyone is different, but based on the findings in the study conducted by Heather Jacobson and Kristen Shuyler I expected more interest. ${ }^{8}$ Because of this revelation, I have decided to deemphasize the socialization aspect in favor of a more "wait and see" approach regarding social relationships. It is something I will remain mindful of as new students cycle in and out of the Documents departmentand, potentially, as the roster of Documents students expands in the future.

Based on the student's mid-year assessment responses and my anticipated needs I have planned ways for my current student employee to contribute to three significant projects during the Spring 2016 term. Documents obligations remain the priority and all tasks are to be worked on during the allotted 37.5 hours/month. By design, there are no strict deadlines in place at this time. I plan to conduct an end-of-the-year assessment at the conclusion of the Spring 2016 term. Before that, the student and I have agreed that he will:

- Help compile data for a research project. Note, this student is not technically a research assistant. As such, our agreement is much less formal (no strict deadlines, no original research work, and nothing that would expose the student to any liability of any kind). 
- Contribute to an oral history project the University Library (specifically the Documents department) and the University's Veterans Affairs office is implementing. We are taking steps to also contribute to the Veterans History Project (Library of Congress). ${ }^{?}$

- Assist with the training of a new Government Documents student worker. ${ }^{10}$

I realize the tasks we have arranged for the upcoming term might seem ambitious for an undergraduate student working part-time in the Government Documents department. That said, this student is a true go-getter with a great attitude and work ethic. While I realize not all student employees are the same, I would argue that Documents supervisors have the opportunity to be picky and ultimately hire exactly this kind of student if that is what they wish to do.

\section{Conclusion}

When given opportunities our students consistently demonstrate that they eager to be challenged and contribute to the library mission. To harness and maintain their enthusiasm, Documents supervisors need to be deliberate in their hiring and supervisory practices from the very beginning of the process. Doing so even at the interview and hiring stages ensures we have the most qualified and best-prepared students possible working for us. Interview students like you would interview candidates for a fulltime staff position. Be upfront about expectations and your desire to partner with new hires to set and achieve highimpact goals. Bring existing student employees onboard early in the training process to convey expectations and facilitate peerto-peer learning. Introduce students to staff and faculty in other departments-and introduce them to administration, too. Encourage cross-training and be available to train other student employees or have your student do it under your supervision.

While not all students will feel comfortable proposing new projects or solutions to existing ones, we can always encourage our student workers to speak up and hear them out when they do; they might surprise us. Documents supervisors have a great opportunity to both challenge and learn from their student employees so long as they are willing and able to be deliberate, flexible, and ambitious. Our students might not ever approach us with ideas first, but that should not prevent us from challenging them and encouraging them to participate in higher-order tasks and assignments.

Josh Sopiarz (jsopiarz@govst.edu) is Assistant Professor, Reference Librarian for the Social Sciences and Government Documents Coordinator, Governors State University.

\section{References}

1. Bradley P. Tolpannen and Janice Derr, "A Survey of the Duties and Job Performance of Student Assistants in Access Services," Journal of Access Services 6, no. 3 (2009): 316.

2. Ibid, 321 .

3. Ibid.

4. Bella Karr Gerlich, "Rethinking the Contributions of student Employees to Library Services," Library Administration \& Management 16, no. 3 (2002): 146-50.

5. Lori S. Mestre and Jessica M. LeCrone, "Elevating the Student Assistant: An Integrated Development Program for Student Library Assistants," College \& Undergraduate Libraries 22, no. 1 (2015): 3.

6. Ibid.

7. "High-Impact Educational Practices," Association of American Colleges \& Universities, www.aacu.org/leap/ hips.

8. Heather A. Jacobson and Kristen S. Shuyler, "Student Perceptions of Academic and Social Effects of Working in a University Library," Reference Services Review 41, no. 3 (2013): 547-65.

9. Library of Congress, Veterans History Project, www.loc .gov/vets.

10. For some other ideas that may be adapted to ocuments work see Firouzeh Logan, "Student Workers: Essential Partners in the Twenty-First Century Academic Library," Public Services Quarterly 8, no. 4 (2012): 316-25. 